\title{
Inverse Relationship Between Education and Parietotemporal Perfusion Deficit in Alzheimer's Disease
}

\author{
Yaakov Stern, PhD, Gene E. Alexander, PhD, Isak Prohovnik, PhD, and Richard Mayeux, MD
}

\begin{abstract}
A higher prevalence of dementia in individuals with fewer years of education has suggested that education may protect against Alzheimer's disease (AD). We tested whether individuals with more years of education have a more advanced $A D$ before it is clinically evident. As a measure of pathophysiological severity, we quantified regional cerebral blood flow (rCBF), by the ${ }^{133}$ Xenon inhalation technique; a specific pattern of flow reduction in the parietotemporal cortex corresponds to $A D$ pathology. In 3 groups of patients with probable $A D$, matched for clinical measures of dementia severity but with varying levels of education, whole-cortex mean flows were comparable. However, the parietotemporal perfusion deficit was significantly greater in the group with the highest level of education, indicating that $\mathrm{AD}$ was more advanced in this group. We conclude that education or its covariates or both may provide a reserve that compensates for the neuropathological changes of AD and delays the onset of its clinical manifestations.
\end{abstract}

Stern Y, Alexander GE, Prohovnik I, Mayeux R. Inverse relationship between education and parietotemporal perfusion deficit in Alzheimer's disease. Ann Neurol 1992;32:371-375

The relationship between education and dementia is controversial. Several epidemiological studies report a higher prevalence of Alzheimer's disease (AD) in individuals with fewer years of education [1]. One interpretation of these findings has been that education represents a confound; individuals with lower educational levels perform more poorly on screening tests for dementia, which results in a higher rate of detection. This in turn introduces high false-positive rates in individuals with low education and high false-negative rates in those with more education [2]. A second interpretation is that the prevalence of $A D$ in the higher education ranges may actually be lower, indicating protection $[3,4]$.

A hypothesis that supports this second interpretation is tested in the present study; that is, education may actually provide a reserve that must be depleted to a certain threshold before dementia is clinically manifest and in that sense it protects against the emergence of the clinical features of $A D$. If this is the case, we would predict that years of education would correlate inversely with degree of $\mathrm{AD}$ pathology, given comparable clinical severity of dementia. To evaluate the degree of $A D$ pathology, we used regional cerebral blood flow (rCBF), assessed with the ${ }^{133}$ Xenon inhalation method. Using both $\mathrm{rCBF}$ and positron emission to- mographic scanning, a characteristic parietotemporal perfusion and metabolic deficit has been demonstrated in patients with $\mathrm{AD}$ [5-8]. This pattern of flow reduction is sensitive and specific, as follows: (1) It is well correlated in AD patients with postmortem histological diagnosis [9]. (2) It is present from the early stages of disease [10]. (3) It discriminates $\mathrm{AD}$ from major depressive disorder, multiinfarct dementia, Pick's disease, and normal aging [11-14]. And (4) it correlates with disease severity and increases with disease progression [7]. Postmortem studies have also shown the maximal histopathology in similar parietotemporal areas [15].

If advanced education increases the threshold for detecting the clinical manifestations of $\mathrm{AD}$, then more severe pathological changes would be present in patients with higher education and be reflected as reduced perfusion in the parietotemporal cortex. Therefore, in patients matched for overall severity of dementia, the parietotemporal flow deficit would be greater in those with more years of education.
Methods
Subjects
Fifty-eight consecutive patients with $\mathrm{AD}$ accepted into a lon- gitudinal rCBF study provided informed consent for this

From the Departments of Neurology, Psychiatry, and Radiology, Columbia University, College of Physicians and Surgeons; Memory Disorders Clinic in the New York State Psychiatric Institute; The Alzheimer's Disease Research Center in the City of New York; and the Department of Brain Imaging, New York Stare Psychiatric Institute, New York, NY.
Received Oct 23, 1991, and in revised form Mar 3, 1992. Accepted for publication Mar 8, 1992.

Address correspondence to Dr Stern, Neurological Institure, 710 West 168th St, New York, NY 10032. 
study. Before rCBF measurement, all underwent extensive neurological and neuropsychological evaluations and met DSM-III-R criteria for dementia [16] and NINCDSADRDA (National Institute of Neurological and Communicative Disorders and Stroke-Alzheimer's Disease and Related Disorders Association) criteria for probable Alzheimer's disease (pAD) [17]. Computed tomographic scanning or magnetic resonance imaging was used to rule out patients with vascular lesions or tumors. Electroencephalography, lumbar puncture, and laboratory tests (urinalysis, SMA20, complete blood cell count, $B_{12}$ levels, and thyroid function tests) were within normal limits. Psychiatric screening was used to assess the potential contribution of depression. Detailed, structured neurological and medical evaluation ruled out other neurological conditions. Neuropsychological evaluation included tests of memory (verbal and nonverbal, immediate and remote), language, visuospatial ability, abstract reasoning, general intellectual function (IQ), and praxis. Subjects with a history of prior neurological or psychiatric illness were excluded. There was no a priori selection of patients based on education, and rCBF played no role in the diagnostic process.

\section{Procedures}

CLINICAL MEASURES. Indices to assess the severity of the disease were administered separately from the neuropsychological battery administered to confirm diagnosis. The modified Mini-Mental Status Examination (mMMS) was used to estimate general intellectual function $[18,19]$. This brief, 57-point scale tests memory, orientation, attention, language, and constructional abilities, and has established validity and reliability [20]. Change in the ability to perform day-to-day activities of daily living (ADL) also occurs in pAD and the degree of impairment in ADL can be independent of intellectual dysfunction [21]. The Blessed Dementia Rating Scale, Part 1 (BDRS) [22] was used to rate ADL. Duration of clinical symptoms and age at onset were estimated from an interview of the patient and all available informants.

rCBF. $\mathrm{rCBF}$ was measured as described elsewhere [10] with 32 scintillation detectors. All measurements were made under resting, supine conditions in a quiet, darkened room with weighted blinders placed over the subjects' eyes. Head positioning was maintained in relation to light markers aligned to the canthomeatal line. Extensive quality control standards were used [23]. Clearance curves were analyzed with a six-unknown model (M2) that provides greater sensitivity and accuracy under low-flow conditions [24]. We chose to use the initial slope index (ISI) derived from the model as the dependent variable because this index showed the best discrimination of $\mathrm{AD}$ and controls in a previous study [10]. ISI is a measure of cerebral blood flow dominated by gray matter but stabilized by white matter. This variable does not depend on partition coefficients, but corresponds to $\mathrm{m} / 100$ $\mathrm{gm} / \mathrm{min}$ if the blood-brain partition coefficient for Xe is assumed to be 1.0 in the tissue volume of interest.

Global perfusion was examined by using whole-cortex mean values. When examining regional flows at specific detectors, we eliminated general flow effects by computing a relative distribution value for each region consisting of normalization by the global mean flow for each subject. We also calculated a parietal index, which consists of the sum of two parietal lobe detectors (P1 and P3) divided by the sum of two reference detectors $(\mathrm{O} 2$ and $\mathrm{C} 1)$. This index is typically reduced in patients with $A D$, but not in controls or those with other dementing illnesses $[10,25]$.

At the time of $\mathrm{rCBF}$, end tidal $\mathrm{PCO}_{2}$ was assessed during the 11-minute $\mathrm{rCBF}$ measurement period. Blood pressure was obtained after the measurement.

\section{Statistical Analysis}

Patients were initially subdivided into 3 ranges of education, and global and regional flows were compared using analysis of variance (ANOVA). We first investigated the possibility of a systematic relation between lateralized flow measures and educational level by performing a $2 \times 3$ ANOVA, treating the right and left hemisphere values as repeated measures and investigating the interaction between hemisphere and education level. Because neither interactions nor main effects were significant, we averaged ISI values from right and left detectors, to simplify subsequent comparisons, which were made using one-way ANOVA.

Correlational analyses investigated the relation between education and rCBF. Stepwise multiple regression was used to estimate the variance of selected $\mathrm{rCBF}$ indices that is explained by education after controlling for other relevant clinical indices.

\section{Results}

Table 1 summarizes the demographic and clinical characteristics of the following three education groups: less than 12 years of education (range, 3-11 yr), high school graduate (12 yr), and greater than high school (range, 13-24 yr). Based on one-way ANOVA and $\chi^{2}$ tests as appropriate, the three groups did not differ on any clinical measure or demographic characteristic assessed.

Both mean whole brain flow and the parietal index were low, consistent with previous reports in pAD [10, $23]$. The values were inversely related to education, but did not differ significantly across groups (Table 2). However, exclusion of a single extreme outlier in the lowest education group yielded significant differences in the expected direction for the parietal index.

For each education group, percentage of flow relative to whole brain at individual detectors is illustrated in the Figure, and values that differed significantly across groups are summarized in Table 2. Significant differences were seen across the education groups at the following three detectors in the parietotemporal area: $\mathrm{T} 3, \mathrm{P} 3$, and $\mathrm{O} 2$. In each case, post hoc analyses revealed greater flow reduction in the highest education group relative to the other groups. The most pronounced decline in relative flow was noted at the P3 detector.

Correlation coefficients were calculated to investigate the relation between education, treated as a continuous variable, and percentage of flow at each de- 
Table 1. Summary of Demographics and Clinical Measures for the Three Education Groups

\begin{tabular}{|c|c|c|c|c|}
\hline & \multicolumn{3}{|c|}{ Mean (SD) } & \multirow[b]{2}{*}{$p$} \\
\hline & Below HS & HS Graduate & Above HS & \\
\hline n & 18 & 18 & 22 & \\
\hline Age (yr) & $69.4(10.3)$ & $68.6(11.2)$ & $65.9(8.1)$ & NS \\
\hline Education (yr) & $7.8(2.6)$ & $12.0(0.0)$ & $17.3(3.1)$ & 0.01 \\
\hline Age at onset (yr) & $66.0(10.0)$ & $64.4(11.2)$ & $61.5(9.4)$ & NS \\
\hline Duration (yr) & $4.1(2.5)$ & $4.0(2.4)$ & $4.5(2.6)$ & NS \\
\hline mMMS & $29.7(11.0)$ & $28.3(10.6)$ & $32.8(9.3)$ & NS \\
\hline BDRS & $9.5(4.6)$ & $9.5(4.0)$ & $10.3(4.4)$ & NS \\
\hline BP sys (mm Hg) & $137.4(19.9)$ & $134.0(16.2)$ & $130.9(15.0)$ & NS \\
\hline $\mathrm{BP}$ dia (mm Hg) & $76.4(11.2)$ & $76.7(11.9)$ & $74.2(12.6)$ & NS \\
\hline $\mathrm{PcO}_{2}(\mathrm{~mm} \mathrm{Hg})$ & $36.6(4.4)$ & $36.7(4.5)$ & $37.4(4.9)$ & NS \\
\hline Non-white $(\%)$ & 11.1 & 5.5 & 9.1 & NS \\
\hline Right handed $(\%)$ & 72.2 & 88.8 & 90.9 & NS \\
\hline English, first language (\%) & 61.1 & 77.7 & 90.9 & 0.08 \\
\hline Female $(\%)$ & 72.2 & 72.2 & 45.5 & NS \\
\hline
\end{tabular}

HS = high school; mMMS = modified Mini-Mental Status examination; BDRS = Blessed Dementia Rating Scale; BP sys = systolic blood pressure; $\mathrm{BP}$ dia $=$ diastolic blood pressure; $\mathrm{PCO}_{2}=$ partial pressure carbon dioxide; $\mathrm{NS}=$ not significant.

Table 2. Summary of Cortical Perfusion Values for the Three Education Groups

\begin{tabular}{|c|c|c|c|c|}
\hline & \multicolumn{3}{|c|}{ Mean (SD) } & \multirow[b]{2}{*}{$p$} \\
\hline & Below HS & HS Graduate & Above HS & \\
\hline $\mathrm{n}$ & 18 & 18 & 22 & \\
\hline Mean flow & $43.5 \quad(8.5)$ & $42.2 \quad(8.7)$ & $39.3 \quad(6.3)$ & NS \\
\hline Parietal index & $0.936(0.064)$ & $0.915(0.054)$ & $0.903(0.051)$ & NS \\
\hline F5 & $1.037(0.053)$ & $1.034(0.033)$ & $1.074(0.048)^{\mathrm{a}}$ & 0.02 \\
\hline $\mathrm{T} 3$ & $0.991(0.057)$ & $1.005(0.043)$ & $0.960(0.066)^{\mathrm{b}}$ & 0.05 \\
\hline P3 & $0.937(0.06)$ & $0.921(0.053)$ & $0.883(0.046)^{\mathrm{a}}$ & 0.01 \\
\hline $\mathrm{O} 2$ & $1.013(0.044)$ & $1.025(0.034)$ & $0.987(0.03)^{\mathrm{a}}$ & 0.01 \\
\hline
\end{tabular}

Mean flow represents actual blood flow in initial slope index units. The remaining items are flows relative to reference areas (parietal index) or to global flow for individual detectors, and are averaged across right and left hemispheres. $p$ values are for one-way analyses of variance with superscript letters summarizing follow-up pairwise comparisons.

${ }^{\mathrm{a}}$ Differs significantly from both other groups.

${ }^{b}$ Differs significantly from the high school graduate group.

$\mathrm{HS}=$ high school; parietal index = flow in the parietal region (P1, P3 detectors) divided by perirolandic (C1) and occipital (O2) regions; NS $=$ not significant.

tector. Significant negative correlations, suggesting reduced flow associated with more education, occurred at the $\mathrm{O} 1$ and $\mathrm{P} 3$ detectors $(r=-0.259$ and -0.361 , respectively, $p<0.05$ for both). A significant positive correlation was observed at the F5 detector $(r=0.299$, $p<0.05$ ) with higher education associated with relatively increased flow, that is, less decreased than in other regions.

Because reduced flow at the P3 detector best discriminated AD patients and matched controls in a previous study [10], we explored the relation between education and flow at this detector using multiple linear regression. Using P3 percentage of flow as the dependent measure, we forced the following 4 variables that assess dementia severity into the regression model: mMMS, BDRS, age, and duration. The model ac- counted for $15.1 \%$ of the variance in $\mathrm{P} 3$ flow. We then added education to the model to evaluate the increment in variance of $\mathrm{P} 3$ flow explained by education and $28.6 \%$ of the variance in $\mathrm{P} 3$ was explained, an increment of $13.5 \%$. This significant increment $(F[1,51\}=9.46, p<0.01)$ suggests that after statistically controlling for variations in the clinical severity of dementia, education is strongly related to the reduction in flow at this detector.

A similar regression analysis was also calculated for the parietal index. Before including education, the severity measures accounted for $14.4 \%$ of the variance in the index. When education was added to the model, it accounted for $23.3 \%$ of the variance in the parietal index, a significant increase $(F[1,51]=5.79, p<$ $0.05)$. 


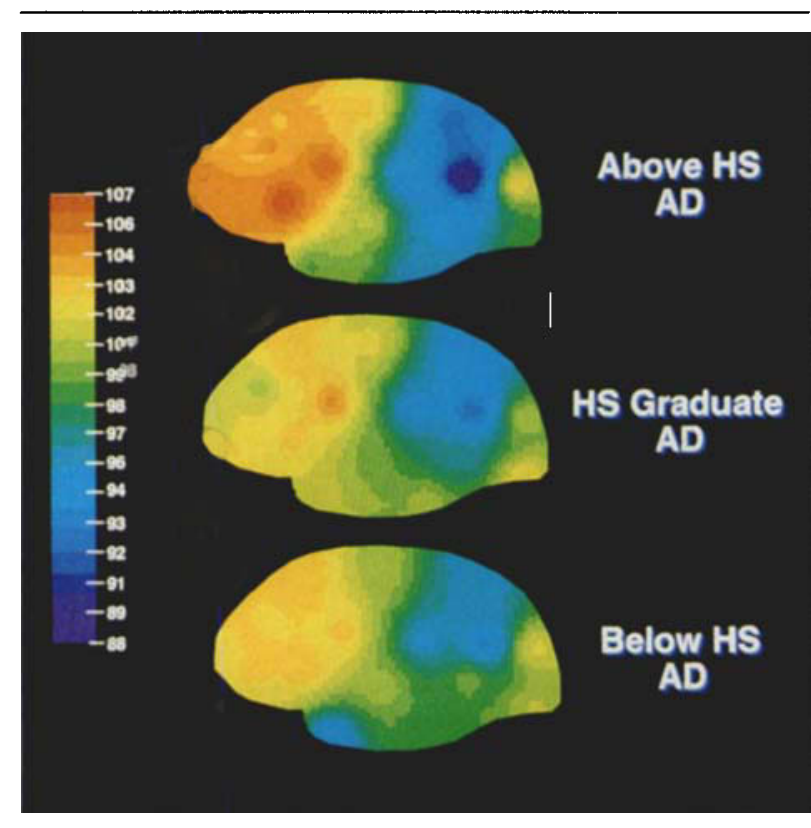

Comparison of relative perfusion in the three educational level AD groups. Regional cerebral blood flow is expressed relative to global flow at each detector, averaged across right and left hemispheres. The bigh end of the color scale (i.e., red) indicates relatively higher cortical perfusion values expressed as a percentage of whole cortex mean initial slope index, whereas the low end of the scale (i.e., blue) represents lower flows relative to global mean perfusion. Note the relative reductions of perfusion in the parietotemporal region for all three $A D$ groups with a markedly greater parietotemporal deficit among patients with above high school educations. $H S=$ high school; $A D=$ Alzheimer's disease.

\section{Additional Analyses}

The distribution of English as a first language was not significantly different across groups but approached significance. To evaluate the potential effects of this variable, all described analyses were recalculated, after stratifying by first language. In no case did first language status contribute any significant variance.

A separate group of 34 nondemented controls were also assessed with identical rCBF and clinical procedures. Education ranged from 8 to 18 years, but mean age was comparable with the $\mathrm{pAD}$ patients. There was no significant correlation between flow at any detector and education. Although range of education is truncated in the controls, it does include education levels whose flow differed significantly in the pAD patients. This suggests that the relation between education and flow is specific to the demented group.

\section{Discussion}

This study offers physiological evidence that education provides a reserve against the clinical expression of $A D$. Our $\mathrm{rCBF}$ data indicate an inverse relation between education and cerebral perfusion. Although global perfusion, which is not specific to $A D$, was comparable across education groups, patients with more education had the greatest perfusion deficits in the area where flow reduction is specific to $A D$.

Interpretation of these findings relies on several assumptions. The first assumption is that years of education reflects cognitive capacity. Clearly not all individuals reach the level of educational attainment consistent with their potential, and the converse is also true. In addition, in this elderly group, expectations for education beyond high school might be subject to cohort effects where older subjects are less likely to complete higher education. Despite these considerations, a general relation between education and intellectual ability is a reasonable assumption. If a better measure of innate intellectual capacity were available, the relations observed here might be stronger. It is also possible that the experience of education itself provides a set of cognitive tools that allow the individual to compensate for the underlying pathological changes that occur as $\mathrm{AD}$ progresses.

A second assumption is that $\mathrm{rCBF}$ is an effective measure of the $\mathrm{AD}$ disease process. The sensitivity and specificity of the regional $\mathrm{rCBF}$ changes in $\mathrm{AD}$ has already been discussed. The precise cause of the flow defect is still unknown, but the distribution has considerable overlap with the cortical areas with the greatest density of histopathological abnormalities, including loss of large neurons, neuritic plaques, and neurofibrillary tangles [26-28]. The focal parietotemporal abnormality may well be related to a cholinergic deficit because nicotinic receptor blockade in normal subjects models it [29]. This functional lesion may also represent an anatomical lesion, that is, local neuronal loss. A unique case report by McGeer and colleagues [30] strongly implicated local necrosis and gliosis as the major determinant on focal glucose metabolism deficits in AD. Because the metabolic coupling of local perfusion is known to be intact in AD [31], rCBF may be considered to reflect neuronal integrity and synaptic activity of the cortex. Regardless of the specific index of degeneration used, overall estimates of local degeneration correlate well in their topographic distribution with rCBF [32]. It is therefore reasonable to assume that the flow reduction is an index of the physiological changes of $\mathrm{AD}$.

This study does not indicate that education affords some type of immunity to the $A D$ process. On the contrary, $\mathrm{AD}$ occurs independently of education. Rather, if we assume that level of education in some way reflects cognitive capacity or stores, then the present data suggest that this might delay the clinical manifestations of the AD. Dementia was not detected in the higher educated patients until functioning was impaired to the same degree as that in the lower education patients. Although estimates of duration of illness 
since the onset of symptoms and functional incapacity are comparable across the three education groups, we propose that the $\mathrm{AD}$ was present longer in the patients with higher education, even though it was not clinically evident.

This work was supported by federal Grants AG07370, AG07232, AG05433, and AG08702, the Charles S. Robertson Memorial Gift for Alzheimer's Disease, and the Jean and Louis Dreyfus Foundation.

This work was presented in part at the 21st Annual Meeting of the Society for Neuroscience, New Orleans, LA, November 10-15, 1991.

We thank Drs Eric Kandel and Barry Gurland for their helpful comments, Lynn Weingarten, RN, for her assistance in data collection, and Claire Metz, $\mathrm{PhD}$, for her programming efforts in producing the color imaging software.

\section{References}

1. Zhang MY, Katzman R, Salmon D, et al. The prevalence of dementia and Alzheimer's disease in Shanghai, China: impact of age, gender, and education. Ann Neurol 1990;27:428-437

2. Kittner SJ, White LR, Farmer ME, et al. Methodological issues in screening for dementia: the problem of education adjustment. J Chronic Dis 1986;39:163-170

3. Berkman LF. The association between educational attainment and mental status examinations: of etiologic significance for senile dementias or not? J Chronic Dis 1986;39:171-174

4. Gurland BJ. The borderlands of dementia: the influence of sociocultural characteristics on rates of dementia occurring in the senium. Aging 1981;15:61-84

5. Risberg J, Gustafson L, Prohovnik I. Regional cerebral blood flow measurements by ${ }^{133} \mathrm{Xe}$ inhalation: applications in neuropsychology and psychiatry. In: Juge O, Donath A, eds. Progress in Nuclear Medicine, Vol 7. Basel, Switzerland: Karger, 1981: 82-94

6. Friedland RA, Budinger TF, Ganz E, et al. Regional cerebral metabolic alterations in dementia of the Alzheimer type: positron emission tomography with $\left[{ }^{18} \mathrm{~F}\right]$ fluorodeoxyglucose. J Comput Assist Tomogr 1983;7:590-598

7. Foster NL, Chase TN, Mansi L, et al. Cortical abnormalities in Alzheimer's disease. Ann Neurol 1984;16:649-654

8. Haxby JV, Duara R, Grady CL, et al. Relations between neuropsychological and cerebral metabolic asymmetries in early Alzheimer's disease. J Cereb Blood Flow Metab 1985;5:193-200

9. Risberg J, Gustafson L. 133-Xe cerebral blood flow in dementia and neuropsychiatry research. In: Magistretti $P$, ed. Functional Radionuclide Imaging of the Brain. New York: Raven, 1983: 151-159

10. Prohovnik I, Mayeux R, Sackeim H, et al. Cerebral perfusion as a diagnostic marker of early Alzheimer's disease. Neurology 1988;38:931-937

11. Risberg J, Gustafson L. Regional cerebral blood flow in psychiatric disorders. In: Knezevic S, Maximilian V, Mubrin Z, et al, eds. Handbook of Regional Cerebral Blood Flow. Hillsdale, NJ: Erlbaum, 1988:219-240

12. Sackeim HA, Prohovnik I, Moeller JR, et al. Regional cerebral blood flow in mood disorders: I. Comparison of major depressives and normal controls at rest. Arch Gen Psychiatry 1990;47:60-70

13. Sackeim HA, Prohovnik I, Mayeux R, et al. Abnormal cortical neural networks in major depression and Alzheimer's disease: specificity and relations to clinical state. Biol Psychiatry 1990; 27:41A (Abstract)

14. Prohovnik I, Alexander GE, Tatemichi TK, et al. Cortical perfusion in vascular and Alzheimer's dementia. Neurology 1991;41 (suppl 1):358

15. Friedland RP, Brun A, Budinger TF. Pathological and positron emission tomographic correlations in Alzheimer's disease. Lancet 1985;1:228 (Letter)

16. American Psychiatric Association. Diagnostic and statistical manual. 3rd ed-revised. Washington, DC: APA, 1987

17. McKhann G, Drachman D, Folstein M, et al. Clinical diagnosis of Alzheimer's disease: report of the NINCDS-ADRDA Work Group under the auspices of the Department of Health and Human Services Task Force on Alzheimer's disease. Neurology 1984;34:939-944

18. Folstein MF, Folstein SE, McHugh PR. "Mini-Mental State," a practical method for grading the cognitive state of patients for the clinician. J Psychiatr Res 1975;12:189-198

19. Mayeux R, Stern Y, Rosen J, Leventhal J. Depression, intellectual impairment and Parkinson disease. Neurology 1981;31: 645-650

20. Stern Y, Sano M, Paulson J, Mayeux R. Modified mini-mental state examination: validity and reliability. Neurology 1987;37 (suppl 1):179

21. Mayeux R, Stern Y, Spanton S. Heterogeneity in patients with dementia of the Alzheimer type: evidence for subgroups. Neurology 1985;35:453-461

22. Blessed G, Tomlinson BE, Roth M. The association between quantitative measures of dementia and of senile changes in the cerebral grey matter of elderly subjects. Br J Psychol 1968; 225:797-811

23. Prohovnik I. Data quality, integrity, and interpretation. In: Knezevic S, Maximilian V, Mubrin Z, et al, eds. Handbook of Regional Cerebral Blood Flow. Hillsdale, NJ: Erlbaum, 1988: $51-78$

24. Prohovnik I, Knudsen E, Risberg J. Accuracy of models and algorithms for determination of fast-compartment flow by noninvasive 133-Xe clearance. In: Magistretti $P$, ed. Functional Radionuclide Imaging of the Brain. New York: Raven, 1983:87115

25. Prohovnik I, Alexander GE, Tatemichi TK, Mayeux R. Exploring the nature of the parietotemporal perfusion deficit in $\mathrm{AD}$. J Cereb Blood Flow Metab 1991;1 1(suppl 2):S179 (Abstract)

26. Brun A, Englund $E$. Regional partern of degeneration in Alzheimer's disease: neuronal loss and histopathological grading. Histopathology 1981:5:549-564

27. Pearson RCA, Esiri MM, Hiorns RW, et al. Anatomical correlates of the distribution of pathological changes in the neocortex in Alzheimer's disease. Proc Natl Acad Sci USA 1985;82: 4531-4534

28. Rogers J, Morrison JH. Quantitative morphology and regional and laminar distributions of senile plaques in Alzheimer's disease. J Neurosci 1985;5:2801-2808

29. Gitelman DR, Prohovnik I. Muscarinic and nicotinic contributions to cognitive function and cortical blood flow. Neurobiol Aging 1992;13:313-318

30. McGeer PL, Kamo H, Harrop R, et al. Comparison of PET, MRI and CT with pathology in a proven case of Alzheimer's disease. Neurology 1986;36:1569-1574

31. Frackowiak RS, Pozzilli C, Legg N, et al. Regional cerebral oxygen study and utilization in dementia. Brain 1981;104: 649-654

32. Gustafson L, Brun A, Ingvar DH. Presenile dementia: clinical symptoms, pathoanatomical findings and cerebral blood flow. In: Meyer JS, Lechner H, Reivich M, eds. Cerebrovascular Diseases. Amsterdam: Excerpta Medica, 1977:5-9 